\title{
Rare Multiple Organ Failure Caused by Tumor Lysis and Subsequent Fatal Sepsis After Novel Salvaged Chemotherapy of Rituximab in a Diffuse Large B-cell Lymphoma Patient: A Case Report
}

\section{Xiaojun Guan ( $\nabla$ gxj309@126.com )}

First Affiliated Hospital of Soochow University

Fangkai He

Traditional Chinese Medicine Hospital of Kunshan

\section{Yang Wang}

First Affiliated Hospital of Soochow University

\section{Jiajia Wang}

First Affiliated Hospital of Soochow University

\section{Nan Su}

First Affiliated Hospital of Soochow University

Chao Liu

First Affiliated Hospital of Soochow University

Yehan Zhu

First Affiliated Hospital of Soochow University

\section{Case report}

Keywords: diffuse large B-cell Lymphoma, tumor lysis syndrome, hyperkaliemia, multiple organ failure, rituximab, sepsis

Posted Date: September 17th, 2020

DOl: https://doi.org/10.21203/rs.3.rs-78233/v1

License: (9) This work is licensed under a Creative Commons Attribution 4.0 International License. Read Full License 


\section{Abstract}

Background: Tumor lysis syndrome (TLS) ranges from mild asymptomatic electrolyte derangement to severe organ dysfunction, is rarely associated with diffuse large B-cell Lymphoma (DLBCL). Standard chemotherapy of DLBCL is usually for clinical stable patients, however, it is still unclear for those in critical care situation with organ dysfunction.

Case presentation: Here, we presented a rare case of aggressive bcl-2 and -myc double-positive DLBCL patient, 59-year-old, male, who rapidly progressed to severe multiple organ failure because of spontaneous TLS, and especially hepatic failure is very uncommon. Although the comprehensive treatments inclusive of early glucocorticoid usage, a stent implantation in superior vena cava, pleural and pericardial puncture drainage, anti-shock, non-invasive ventilator support, continuous renal replacement treatment (CRRT), plasma exchange and antibiotics alleviated or inverted the multiple organ failure, the patient was worsened to septic shock and died on the $12^{\text {th }}$ day after new salvage chemotherapy regime with rituximab and cyclophosphamide under CRRT protection.

Conclusions: The current case demonstrated a useful treatment framework to this kind of patient. We should cautiously give glucocorticoid to the patient suspected of lymphoma with high tumor burden. The comprehensive treatments for organ function supporting, especially CRRT, play a crucial role in the recovery of multiple organ failure. In addition, the optimal time and regimen choosing of rescue chemotherapy in severe DLBCL patients still remains a long way to define.

\section{Background}

Tumor lysis syndrome (TLS) being associated with massive cancer cell lysis, is a crucial oncologic emergency and most often occurred in non-Hodgkin lymphoma or acute leukemia, rarely associated with diffuse large B-cell Lymphoma (DLBCL). It is characterized by metabolic abnormalities including hyperkalemia, hyperuricemia, hypocalcemia and hyperphosphatemia, and ranges from mild and transient asymptomatic electrolyte derangement to severe cases of renal failure, cardiac arrhythmias, seizures and death due to multiple organ failure [1, 2]. Rituximab plus combination chemotherapy with cyclophosphamide, doxorubicin, vincristine and prednisone (R-CHOP) is considered the standard therapy for stable DLBCL $[3,4]$. Here, we report a rare aggressive DLBCL patient with high cancer cells burden, who progressed to TLS and subsequent severe multiple organ failure (MOF), in the end, septic shock and death under the revised mini-CHOP chemotherapy regime. We also present a good treatment experience in such severe and complex clinical condition.

\section{Case Presentation}

\section{Stage 1:}


A 59-year-old male was admitted to the cardiovascular medicine department in our hospital on $9^{\text {th }}$ Jun, $2017\left(6.9^{\text {th }}, 2017\right)$ for 2 months of chest tightness and shortness of breath without any positive signs during physical examination. Troponin $(0.01 \mathrm{ng} / \mathrm{ml}), \mathrm{CK}-\mathrm{MB}(6 \mathrm{U} / \mathrm{L})$ and LDH $(294 \mathrm{U} / \mathrm{L})$ levels in serum were normal. Abdominal B ultrasound showed a $2.4 \times 1.9 \mathrm{~cm}$ mass in the spleen and swelled lymph nodes in hepatic hilar region. Importantly, the lung CT scan revealed the normal imaging features in the lung field and lymph nodes swelling in mediastinum (Fig.1 a, b straight arrow).

\section{Stage 2:}

Then, the patient was transferred to our department for endobronchial ultrasound guided tranbronchial needle aspiration (EBUS-TBNA) investigation of mediastinal lymph nodes with primary diagnosis of lymphoma. Thoracic and abnominal enhanced CT scan $\left(6.14^{\text {th }}, 2017\right)$ revealed the swelling lymph nodes in mediastinal (Fig.1 c straight arrow), hilar and retroperitoneal region, severe superior vena cava stenosis (Fig.1 c bent arrow), and low-density shadows in liver and spleen. We implanted a stent in superior vena cava with the routine dexamethasone and low molecular weight heparin usage, and the edema of face, neck and right upper limb was improved. Unexpectedly, both pathological results of right main bronchial mucosa by electronic bronchoscope (Fig.2 a-b) and mediastinal lymph nodes biopsy by EBUS-TBNA (Fig.2 c-d) showed chronic inflammation with focal necrosis $\left(6.20^{\text {th }}, 2017\right.$, on Friday). At that time, the left cervical lymph node was found enlargement and its resection tissue biopsy was pathologically confirmed as DLBCL with LCA +, CD20 +, CD79a +, Bcl-2 +, CD10 -, Bcl-6 +, MUM1+, Ki-67 +, c-myc +, CD3 -, CD2$\left(6.30^{\text {th }}, 2017\right)$. Two days later, on $2^{\text {nd }} \mathrm{Jul}$, chest tightness and breath shortness was suddenly worsened, accompanied by low blood oxygen saturation (85\%), oliguria indicating acute renal dysfunction, and cardiogenic shock with hypotension of $75 / 48 \mathrm{mmHg}$.

\section{Stage 3:}

Emergently, $0.9 \%$ sodium chloride and dopamine were provided against the cardiogenic shock and he was removed to RICU. Non-invasive positive pressure ventilation, furosemidum, hydrocortisone succinate followed by methylprednisolone, and dopamine (highest dose of $10 \mu \mathrm{g} / \mathrm{kg}$.min) subsequently combined norepinephrine (highest dose of $2.0 \mu \mathrm{g} / \mathrm{kg}$. min) were implemented to keep the oxygenation and stable blood pressure. Meanwhile, robustly elevated potassium (highest level $6.66 \mathrm{mmol} / \mathrm{L}$ ) and phosphate levels in serum were measured (table.1). After the usage of furosemidum, calcium gluconate and sodium bicarbonate, at 4 am on $4^{\text {th }}$ Jul, continuous renal replacement treatment (CRRT) was implemented. In addition, increasingly worsened hepatic and renal function dysfunction were observed and the highest levels of ALT, LDH, $\mathrm{Cr}$ and urea were $3483.8 \mathrm{U} / \mathrm{L}, 8140 \mathrm{U} / \mathrm{L}, 232.5 \mu \mathrm{mol} / \mathrm{L}$ and $33.1 \mathrm{mmol} / \mathrm{L}$, respectively (Table 1). Bedside chest X-ray revealed massive pleural effusion in the right chest cavity and significantly enlarged heart shadow consequently identified as pericardial effusion (Fig.2 e-f). The thoracic and pericardial catheterization was instantly implanted and a large amount of yellow pleural effusion and red chylous pericardial effusion were drained. We infused the antibiotics of meropenem, and in the end, 
streptococcus parasanguis was confirmed in pericardial effusion culture. In consideration of severe liver function failure, the two times of plasma exchange using $2500 \mathrm{ml}$ plasma each time was assigned on $6^{\text {th }}$ Jul and $7^{\text {th }}$ Jul. Under the comprehensive interventions including assistant treatments of albumin and blood products, medicine protecting liver function, nutritional support, and so on, the function of organs was obviously improved (Table.1). Vasoactive agents was also down-regulated step by step, thus, the blood pressure fluctuating at the normal level of $120 / 70 \mathrm{mmHg}$ was maintained with $2.0 \mu \mathrm{g} / \mathrm{kg} . \mathrm{min}$ of dopamine on $8^{\text {th }}$ Jul. Simultaneously, chest radiography showed the pleural and pericardial effusion were significantly decreased (Fig. $2 \mathrm{~g}$ ), and the urine output was gradually increased (Table.2). In considering of poor prognosis if there was no further treatment to the primary disease, under advice from a chief consultant hematologist and consent of the patient and the family members, on $12^{\text {th }} \mathrm{Jul}$, we gave him the revised mini-CHOP chemotherapy with $375 \mathrm{mg} / \mathrm{m} 2$ rituximab ( $\mathrm{d} 0,12^{\text {th }} \mathrm{Jul}$ ), $400 \mathrm{mg} / \mathrm{m} 2$ cyclophosphamide (divided into two times infusion, d1, d8), 1 mg/m2 vincristine (d2), 35mg/m2 doxorubicin (divided into two times infusion, d2, d9), and dexamethasone (10mg, d1-d5). To avoid the new tremendous abnormalities of tumor cells lysis, CRRT was performed again 12 hours after cyclophosphamide infusion. Unluckily, on the next day $\left(14^{\text {th }} \mathrm{Jul}\right)$, the patient got worsened again reflected by recurrent breathing difficulty, moist rales, hypotension of $75 / 56 \mathrm{mmHg}$, and $4-8 \mu \mathrm{g} / \mathrm{kg}$.min dopamine and 0.3-0.6 $\mu \mathrm{g} / \mathrm{kg}$.min norepinephrine being needed for maintaining normal blood pressure $(111 / 84$ $\mathrm{mmHg}$ ), although the urinal output was still in stable (Table 2). Therefore, we suspended the subsequent vincristine and doxorubicin infusion. At that time, we observed high fluid load in the last two days (table.2), which maybe contributed to the recurrent acute heart dysfunction and pulmonary edema. After we removed the excessive fluid by CRRT, plasma infusion and intermittent diuretics, the patient again reached on temporary clinical stable condition with blood pressure $(102-138 / 68-89 \mathrm{mmHg})$ with $0.7-2.2$ $\mu \mathrm{g} / \mathrm{kg}$.min dopamine and 0.15-0.3 $\mu \mathrm{g} / \mathrm{kg}$.min norepinephrine. However, in the end, he got further worsened again and we observed multiple herpes zoster with fusion on the cheek and neck skin on $20^{\text {th }}$ Jul. Septic shock with extremely hypotension and low fever was clinically confirmed. Even if the antishock treatments, anti-virus, antibiotics, fluid infusion and CRRT were used, septic shock could not been reversed. On $24^{\text {th }}$ Jul, 45 days after his admission, the blood pressure could not been eventually maintained with the high dose of dopamine and norepinephrine, subsequently, the cardiac and pulmonary arrest occurred and he died at 20:00. 
Table 1

Troponin and electrolytes levels ( $\mathrm{mmol} / \mathrm{L}$ ), cardiac, hepatic and renal function indexes in serum.

\begin{tabular}{|c|c|c|c|c|c|c|c|c|c|c|}
\hline Time & Tn & $\mathrm{K}^{+}$ & $P^{3-}$ & $\mathrm{Ca}^{2+}$ & $\mathrm{Na}^{+}$ & ALT & LDH & $\mathrm{Cr}$ & Urea & ALB \\
\hline 6.10 & 0.01 & 4.1 & 1.11 & 2.39 & 135 & 20.8 & 348 & 62 & 5.4 & 40.5 \\
\hline $7.2^{\mathrm{a}}$ & 0.01 & 5.57 & 1.72 & 2.08 & 119 & 133 & - & 111.7 & 26.6 & - \\
\hline 7.3 & 0.01 & 6.66 & 2.52 & 2.13 & 127.7 & 232.4 & 501 & 166 & 30.5 & 31.7 \\
\hline $7.4^{b}$ & & 5.29 & 1.73 & 2.09 & 136 & 2123 & 3063 & 197 & 33.1 & 30 \\
\hline 7.5 & & 4.94 & 1.59 & 2.19 & 136.9 & 3483.8 & 2974 & 232.5 & 20.1 & 37.4 \\
\hline 7.6 & & 4.27 & 1.07 & 2.14 & 138.7 & 1696.6 & 984 & 200 & 14.8 & 37.3 \\
\hline 7.8 & & & & & & 197.6 & 400 & 200 & 11.9 & - \\
\hline 7.13 & & & & & & 44.9 & 452 & 163 & 13.7 & 31.6 \\
\hline 7.17 & & & & & & 35.9 & 321 & 142 & 12.5 & 30.6 \\
\hline 7.19 & & 4.21 & 1.2 & 2.31 & 138.3 & 31.3 & 266 & 251 & 30.0 & 27.5 \\
\hline 7.23 & & 4.70 & 0.98 & 2.24 & 139.4 & 36.9 & 327 & 162 & 21.5 & 31.3 \\
\hline \multicolumn{11}{|c|}{$\begin{array}{l}\text { a,b Onset of TLS was on } 2^{\text {nd }} 7 \text { and CRRT on } 4^{\text {th }} \text { Jul followed by plasma exchange was implemented. } \\
\text { The organ function was still in stable after chemotherapy. Tn, Troponin (range, 0.00-ng/ml; } \mathrm{K}^{+}, \mathrm{P}^{3-} \text {, } \\
\mathrm{Ca}^{2+}, \mathrm{Na}^{+}(3.5-5.3,0.85-1.51,2.11-2.52,137-147 \mathrm{mmol} / \mathrm{L}) ; \mathrm{ALT} \text {, alanine transaminase }(9-50 \mathrm{U} / \mathrm{L}) \text { ); } \\
\mathrm{AST} \text {, aspertate aminotransferase }(15-40 \mathrm{U} / \mathrm{L}) ; \mathrm{LDH} \text {, lactate dehydrogenase }(120-250 \mathrm{U} / \mathrm{L}) ; \mathrm{CK} \text {, creatine } \\
\text { kinase }(50-310 \mathrm{U} / \mathrm{L}) ; \mathrm{Cr} \text {, creatinine }(57-97 \mu \mathrm{mol} / \mathrm{L}) ; \text { Urea, urea nitrogen }(3.1-8.0 \mathrm{mmol} / \mathrm{L}) ; \mathrm{UA} \text {, uric acid } \\
(150-420 \mu \mathrm{mol} / \mathrm{L}) ; \mathrm{ALB} \text {, albumin }(40-55 \mathrm{~g} / \mathrm{L}) \text {. }\end{array}$} \\
\hline
\end{tabular}

Table 2

Intaking and output liquid levels inclusive of ultrafiltration liquid by CRRT

\begin{tabular}{|c|c|c|c|c|c|c|c|c|c|}
\hline Fluids (ml) & 7.09 & 7.11 & $7.12^{\mathrm{a}}$ & 7.13 & 7.14 & 7.18 & 7.19 & 7.20 & 7.21 \\
\hline Total In-taking & 3220 & 6184 & 8231 & 3734 & 4765 & 3240 & 2968 & 2068 & 5979 \\
\hline Total output & 3262 & 8069 & 6628 & 2231 & 7428 & 2539 & 2500 & 2068 & 6919 \\
\hline Pleural effusion & 550 & 330 & 300 & 350 & 320 & 400 & 200 & 400 & 250 \\
\hline Pericardial effusion & 130 & 35 & 100 & 100 & 75 & 200 & 100 & 30 & - \\
\hline Urine output & 75 & 135 & 80 & 110 & 120 & 1240 & 1600 & 1160 & 950 \\
\hline Ultrafiltration & 2427 & 7429 & 5948 & 1301 & 6863 & - & - & - & 4869 \\
\hline
\end{tabular}




\section{Discussion And Conclusions}

According to management guidelines for DLBCL [5], surgical excisional or incisional biopsy is strongly recommended to obtain adequate tissue for diagnosis. Although core needle biopsies are alternative, it frequently yield small and insufficient samples for diagnostic confirmation. Therefore, in our case, besides the focal necrosis of lymph nodes, the recommendation can partly explain why we did not confirm the diagnosis by the EBUS-TBNA, but by excisional biopsy in cervical lymph node. DLBCL is diagnosed on based of morphological, cytogenetic and molecular analyses. At least two molecular subtypes of DLBCL have been identified by gene expression profiling (GEP): the germinal center B-cell-like (GCB-type) and the activated B-cell-like (ABC-type) [6]. ABC-type predicted a worse prognosis with a $40 \%$ 3-year progression-free survival (PFS) compared to 75\% for the GCB-type [7, 8]. Myc rearrangement, found in approximately $10 \%$ of aggressive B-cell lymphomas, confer a poor prognosis $[9,10]$. Additionally, BCL2 and/or BCL6 rearrangement have been reported in 3\%-14\% DLBCL patients, also associated with a worse prognosis [11-14]. In our current case, the ABC-type GEP with Bcl-2 (+), Bcl-6 (+), MUM1 (+), Ki-67 (+), myc $(+)$ strongly indicated poor prognosis.

DLBCL and non-Hodgkin lymphoma (NHL) with bulky disease defined as LDH > twice the upper limit of normal or tumour size on CT scan regarded as a mass $>10 \mathrm{~cm}$ in diameter are categorized as being at the highest risk of developing TLS [2]. TLS has been reported as a recognized complication of hematologic malignant lymphomas including uncommon form of ALK-positive DLBCL, spontaneous or especially induced by chemotherapy, which is associated with significant morbidity and mortality $[15,16]$. Cairo recommended that those at low and intermediate risk should be actively monitored and offered by hydration +/- allopurinol prophylaxis, however, those at the high risk should be offered rasburicase regarded as a highly effective agent [2]. One single $3 \mathrm{mg}$ rasburicase can prevent TLS in majority of adult high risk haematological malignancies patients, however, close monitor for biochemical and clinical markers of TLS is necessary; once there is any progression evidence, the dose should be repeated daily until TLS markers return to normal; furthermore, if clinical TLS still worsens, rasburicase should be used with a standard dose $(0.2 \mathrm{mg} / \mathrm{kg} /$ day $)$ [17]. A case series of adult lymphoma patients presenting the high risk of TLS received a single fixed dose of rasburicase $(6 \mathrm{mg}$ or $4.5 \mathrm{mg})$ and obtained an improvement of the mean uric acid level and renal function [18]. In the current case, high tumor cells burden, the patient not seeing doctor in time, the delayed confirmative diagnosis because of the two times of pathological investigation, repeated and plausible "routine" glucocorticoids using after stent implanting and the time that he complaining chest tight, lack of rasburicase supplying, multiple disciplinary team communication being not enough timely, all of above contributed to initiation and progression of TLS. In our case, we speculated that TLS firstly resulted to severe acute renal dysfunction and robust hyperkalemia, subsequently, high liquid load and a large amount of pericardial effusion caused to acute heart failure and cardiogenic shock. Meanwhile, respiratory failure occurred because of magnificent pulmonary edema, enlarged heart and plural effusion. Anti-shock treatment, CRRT and non-invasive ventilating were instantly administrated. Especially, the severe hypotension was immediately significantly reversed after 
pericardial puncture drainage with $300 \mathrm{ml}$ necrotic effusion on the first time. Notably, the serious liver function failure in our case is extremely rare in reported TLS cases, thus, plasma exchange was implemented twice. Given that leukocytes, neutrophil percentage, serum procalcitonin and c-reaction protein levels $\left(4.24 \mathrm{ng} / \mathrm{ml}\right.$ and $247 \mathrm{mg} / \mathrm{L}$, respectively on $4^{\text {th }} \mathrm{Jul}$ ) were significantly increased (Table 3) and pericardial effusion culture was positive, antibiotics were routinely infused. Under the comprehensive treatments, hyperkalemia, ALT, AST, LDH, urea and creatine levels were quickly improved or back down to normal levels (table.1). Simultaneously, a series of bedside chest X-ray demonstrated the pericardial and pleural effusion gradually disappeared (Fig. $2 \mathrm{~g}$-h), blood pressure was normally maintained with $2.0 \mu \mathrm{g} / \mathrm{kg}$.min of dopamine using to improve renal blood perfusion, and the NIPPV parameters were low supportive levels, which indicated cardiac and respiratory function was in well status already. In the recovery process, we also observed the urine output was gradually increased and it was $1600 \mathrm{ml}$ without diuretics after half month of CRRT (Table 2).

Table 3

Parameters of blood routine test\BRT囚from admission to discharge

\begin{tabular}{|llllllllll|}
\hline BRT & 6.10 & 7.2 & 7.4 & 7.11 & 7.13 & 7.15 & 7.19 & 7.21 & 7.23 \\
\hline $\mathrm{WBC} \times 10^{9} / \mathrm{L}^{\mathrm{a}}$ & 11.68 & 25.13 & 28.06 & 13.47 & 16.01 & 13.31 & 7.3 & 3.91 & 6.67 \\
\hline $\mathrm{N}(\%)^{\mathrm{b}}$ & 62 & 92 & 94 & 93 & 96 & 96 & 92 & 88 & 90 \\
\hline $\mathrm{L} \times 10^{9} / \mathrm{L}^{\mathrm{c}}$ & 2.27 & 0.88 & 0.67 & 0.39 & 0.23 & 0.37 & 0.46 & 0.34 & 0.52 \\
\hline $\mathrm{Hb} \mathrm{g} / \mathrm{L}^{\mathrm{d}}$ & 150 & 141 & 148 & 109 & 104 & 90 & 82 & 76 & 74 \\
\hline $\mathrm{Plt} \times 10^{9} / \mathrm{L}^{\mathrm{e}}$ & 259 & 257 & 303 & 79 & 90 & 67 & 49 & 55 & 43 \\
\hline aWBC, white blood cell or leukocyte; ${ }^{\mathrm{b}} \mathrm{N}$, neutrophil; ${ }^{\mathrm{C}} \mathrm{L}$, lymphocyte; ${ }^{\mathrm{d}} \mathrm{Hb}$, hemoglobin; ${ }^{\mathrm{e}}$ Plt, platelet. \\
\hline
\end{tabular}

Incorporating the anti-CD20 monoclonal antibody of rituximab into the conventional chemotherapy of cyclophosphamide, doxorubicin, vincristine, and prednisolone (CHOP) significantly improved clinical prognosis of DLBCL patients [19-21]. As a result, rituximab represents a new chemotherapy era and R$\mathrm{CHOP}$ has become the standard chemotherapy regime. Given the relatives of the patient having high positive expectation to chemotherapy and final prognosis, in addition, few reports and little clinical chemotherapy experience in the clinical situation, therefore, after his organs function recovered, we implemented the revised mini-CHOP chemotherapy. In view of cyclophosphamide could being removed by CRRT, we suspended CRRT during cyclophosphamide infusion, and was restarted $12 \mathrm{~h}$ later. Out of our expectation, the patient got worsened and rapidly progressed to septic shock presented by the unstable blood pressure, multiple herpes zoster, thrombocytopenia and lower hemoglobin, but the organ function being still normal (Table 2-3). We considered that the sepsis resulted from robustly decreased lymphocytes counts (Table 3) indicating immune function inhibition (IgG $6.37 \mathrm{~g} / \mathrm{L}$, IgM $0.34 \mathrm{~g} / \mathrm{L}, \mathrm{CD} 19^{+}$ $0.39 \%, \mathrm{CD}^{3+} 82.7 \%, \mathrm{CD}^{4+} 19.28 \%, \mathrm{CD}^{8+} 60.46 \%, \mathrm{CD}^{4+} / \mathrm{CD}^{8+} 0.32$ were confirmed) after rituximab and cyclophosphamide. 
Overall, our report presented a rare and severe multiple organ failure secondary to TLS. As matter of fact, the comprehensive treatments including anti-shock, ventilating support, CRRT, plasma exchange improved or reversed multiple organ failure, demonstrated a useful treatment framework to this kind of patient. In the current case, however, several factors or defects of clinical interventions before TLS onset, for instance, deferred pathology report, corticosteroids usage without routine rasburicase prophylaxis, certainly another key element that the patient did not see a doctor in time and had high tumor burden, all above caused to TLS and subsequent multiple organ failure. Taking the specific circumstance into account, establishing the best chemotherapy decision was difficult and controversial, inclusive of the optimal regimen and schedule of salvage chemotherapy, and it still need a long way to delineated. As our case indicated in the end, immune system inhibition and sequent severe infection progressing septic shock gave the patient "the second hit" to death. At last, the close and timely multi-disciplinary communication is crucial during the whole diagnosis and treatment process in such complex clinical situation.

\section{List Of Abbreviations}

TLS: Tumor lysis syndrome

DLBCL: diffuse large B-cell lymphoma

EBUS-TBNA: endobronchial ultrasound guided tranbronchial needle aspiration

GEP: gene expression profiling

MOF: multiple organ failure

CRRT: continuous renal replacement treatment

R-CHOP: rituximab cyclophosphamide, doxorubicin, vincristine and prednisone

\section{Declarations}

\section{Ethics approval and consent to participate}

Ethics approval and consent to participate were obtained.

\section{Consent for publication}

All co-authors consent for this publication.

\section{Availability of data and material}


Data are available at the Department of Respiratory and Critical Care Medicine, the First Affiliated Hospital of Soochow University.

\section{Competing interests}

All co-authors declare no conflict of interest.

\section{Funding}

No funding was received for this work.

\section{Authors' contributions}

All co-authors contributed equally to this work. All authors read and approved the final manuscript.

\section{Acknowledgement}

The Authors are grateful to chief hematologist of Hai-wen Huang in the department of hematology in our hospital for the clinical treatment advice about primary disease of DLBCL.

\section{Authors' information}

Xiaojun Guan and Fangkai He are the joint first authors.

\section{References}

1. Howard SC, Jones DP, Pui CH. The tumor lysis syndrome. N Engl J Med. 2011;364(19):1844-54.

2. Cairo MS, Coiffier B, Reiter A, Younes A, Panel TLSE. Recommendations for the evaluation of risk and prophylaxis of tumour lysis syndrome (TLS) in adults and children with malignant diseases: an expert TLS panel consensus. Br J Haematol. 2010;149(4):578-86.

3. Schelker RC, Herr W, Reichle A, Vogelhuber M. Low-dose trofosfamide plus rituximab is an effective and safe treatment for diffuse large B-cell lymphoma of the elderly: a single center experience. BMC Cancer. 2018;18(1):1000.

4. Drott $\mathrm{K}$, Hagberg H, Papworth K, Relander T, Jerkeman M. Valproate in combination with rituximab and CHOP as first-line therapy in diffuse large B-cell lymphoma (VALFRID). Blood Adv. 2018;2(12):1386-92.

5. Chaganti S, Illidge T, Barrington S, McKay P, Linton K, Cwynarski K, et al. Guidelines for the management of diffuse large B-cell lymphoma. Br J Haematol. 2016;174(1):43-56. 
6. Alizadeh AA, Eisen MB, Davis RE, Ma C, Lossos IS, Rosenwald A, et al. Distinct types of diffuse large B-cell lymphoma identified by gene expression profiling. Nature. 2000;403(6769):503-11.

7. Staudt LM. Molecular diagnosis of the hematologic cancers. N Engl J Med. 2003;348(18):1777-85.

8. Lenz G, Wright G, Dave SS, Xiao W, Powell J, Zhao H, et al. Stromal gene signatures in large-B-cell lymphomas. N Engl J Med. 2008;359(22):2313-23.

9. Dunleavy K, Fanale MA, Abramson JS, Noy A, Caimi PF, Pittaluga S, et al. Dose-adjusted EPOCH-R (etoposide, prednisone, vincristine, cyclophosphamide, doxorubicin, and rituximab) in untreated aggressive diffuse large B-cell lymphoma with MYC rearrangement: a prospective, multicentre, single-arm phase 2 study. Lancet Haematol. 2018;5(12):e609-e17.

10. Savage KJ, Johnson NA, Ben-Neriah S, Connors JM, Sehn LH, Farinha P, et al. MYC gene rearrangements are associated with a poor prognosis in diffuse large B-cell lymphoma patients treated with R-CHOP chemotherapy. Blood. 2009;114(17):3533-7.

11. Li S, Seegmiller AC, Lin P, Wang XJ, Miranda RN, Bhagavathi S, et al. B-cell lymphomas with concurrent MYC and BCL2 abnormalities other than translocations behave similarly to MYC/BCL2 double-hit lymphomas. Mod Pathol. 2015;28(2):208-17.

12. Aukema SM, Kreuz M, Kohler CW, Rosolowski M, Hasenclever D, Hummel M, et al. Biological characterization of adult MYC-translocation-positive mature B-cell lymphomas other than molecular Burkitt lymphoma. Haematologica. 2014;99(4):726-35.

13. Green TM, Young KH, Visco C, Xu-Monette ZY, Orazi A, Go RS, et al. Immunohistochemical double-hit score is a strong predictor of outcome in patients with diffuse large B-cell lymphoma treated with rituximab plus cyclophosphamide, doxorubicin, vincristine, and prednisone. J Clin Oncol. 2012;30(28):3460-7.

14. Scott DW, Mottok A, Ennishi D, Wright GW, Farinha P, Ben-Neriah S, et al. Prognostic Significance of Diffuse Large B-Cell Lymphoma Cell of Origin Determined by Digital Gene Expression in FormalinFixed Paraffin-Embedded Tissue Biopsies. J Clin Oncol. 2015;33(26):2848-56.

15. Chapman-Fredricks J, Blieden C, Sandoval JD, Ernani V, Ikpatt OF. Acute spontaneous tumor lysis syndrome as the initial presentation of ALK-positive diffuse large B-cell lymphoma. Appl Immunohistochem Mol Morphol. 2014;22(4):317-21.

16. Yang B, Lu XC, Yu RL, Chi XH, Zhang WY, Zhu HL, et al. Diagnosis and treatment of rituximab-induced acute tumor lysis syndrome in patients with diffuse large B-cell lymphoma. Am J Med Sci. 2012;343(4):337-41.

17. Jones GL, Will A, Jackson GH, Webb NJ, Rule S, British Committee for Standards in H. Guidelines for the management of tumour lysis syndrome in adults and children with haematological malignancies on behalf of the British Committee for Standards in Haematology. Br J Haematol. 2015;169(5):66171.

18. Chiang J, Chan A, Lian T, Tay K, Quek R, Tao M, et al. Management of tumor lysis syndrome with a single fixed dose of rasburicase in Asian lymphoma patients: a case series and literature review. Asia Pac J Clin Oncol. 2011;7(4):351-6. 
19. Coiffier B, Lepage E, Briere J, Herbrecht R, Tilly H, Bouabdallah R, et al. CHOP chemotherapy plus rituximab compared with $\mathrm{CHOP}$ alone in elderly patients with diffuse large-B-cell lymphoma. N Engl J Med. 2002;346(4):235-42.

20. Pfreundschuh M, Trumper L, Osterborg A, Pettengell R, Trneny M, Imrie K, et al. CHOP-like chemotherapy plus rituximab versus $\mathrm{CHOP}$-like chemotherapy alone in young patients with goodprognosis diffuse large-B-cell lymphoma: a randomised controlled trial by the MabThera International Trial (MInT) Group. Lancet Oncol. 2006;7(5):379-91.

21. Seki R, Ohshima K, Nagafuji K, Fujisaki T, Uike N, Kawano F, et al. Rituximab in combination with CHOP chemotherapy for the treatment of diffuse large B cell lymphoma in Japan: a retrospective analysis of 1,057 cases from Kyushu Lymphoma Study Group. Int J Hematol. 2010;91(2):258-66.

\section{Figures}

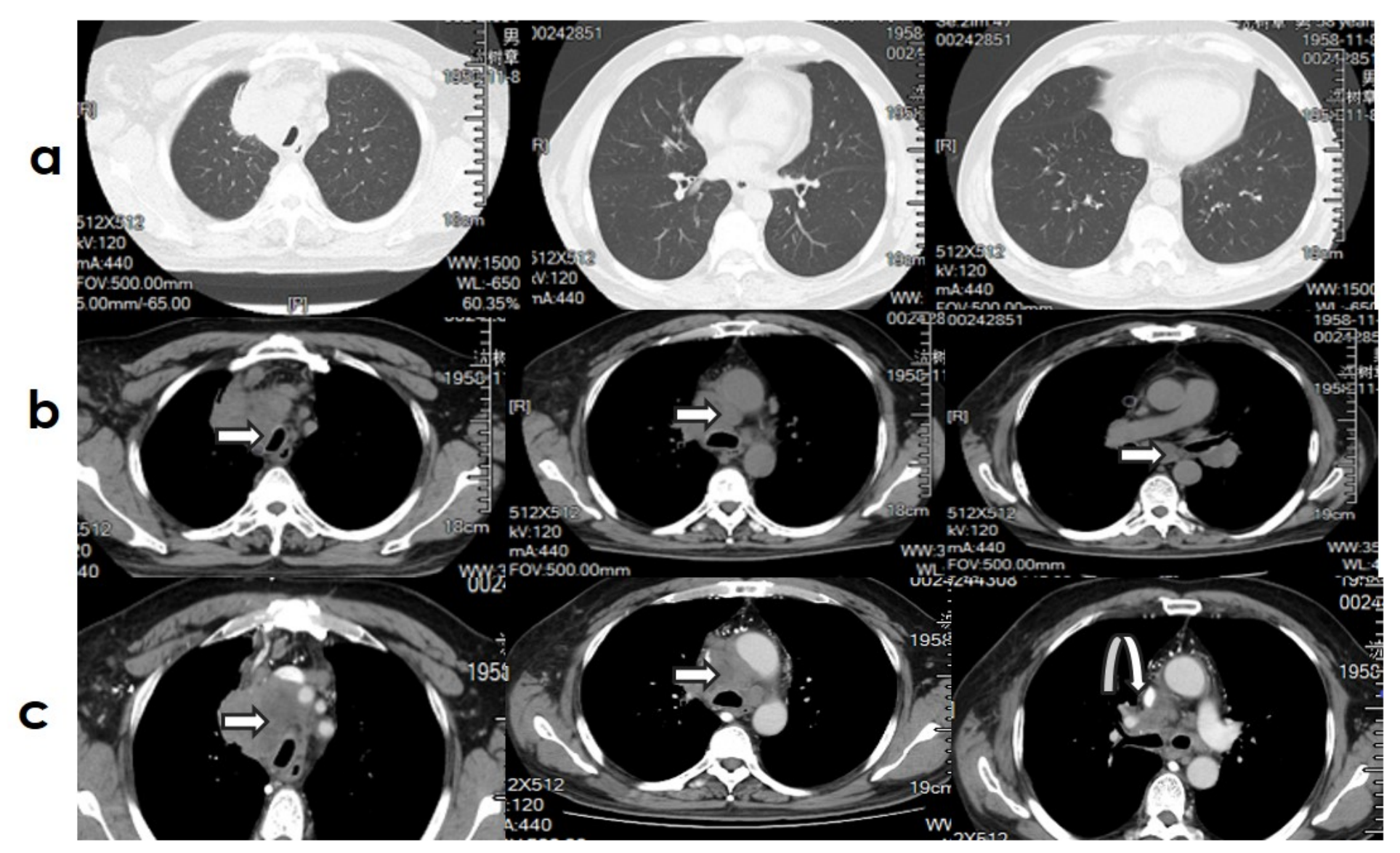

\section{Figure 1}

The chest CT without/with contrast scan before TLS onset. Chest CT scan showed the normal imaging features in the lung field (a) and swelling lymph nodes in mediastinal region which were further confirmed on the chest CT scan with contrast (b-c, straight arrow)), furthermore, almost fully obstructive superior vena cava was observed on chest CT with contrast (c, bent arrow). 


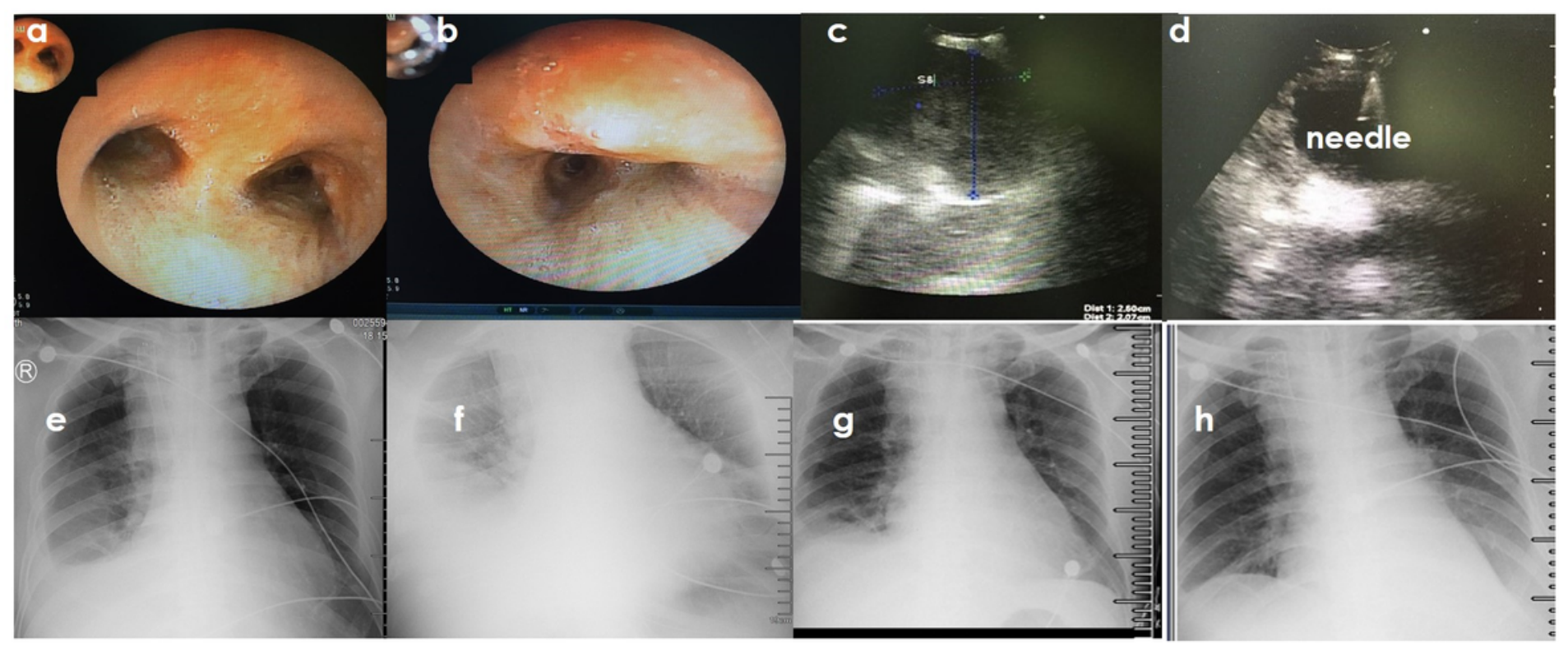

\section{Figure 2}

Routine bronchoscopy investigation and dynamic chest X-ray. Carina (a), mucous lesion and stenosis of right main bronchus (b) were demonstrated by bronchoscopy; sub-carina lymph nodes swelling (c) was observed and needle aspiration was performed by EBUS-TBNA (d). On the beginning of TLS, small

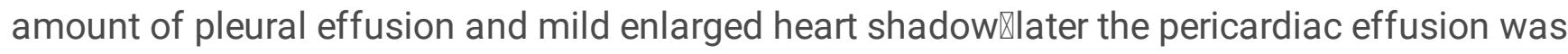
confirmed $\rrbracket$ were found on 3rd 7 (at 18:15, e) and massive pleural and pericardiac effusion were identified on 5 th 7 (at 14:40, f). After the comprehensive treatments, abnormal imageological changes got recovery to almost normal on 10th $7(\mathrm{~g})$ and 18th $7(\mathrm{~h})$. 